This item was submitted to Loughborough's Research Repository by the author.

Items in Figshare are protected by copyright, with all rights reserved, unless otherwise indicated.

\title{
Cure efficiency of dodecyl succinic anhydride as a cross-linking agent for elastomer blends based on epoxidized natural rubber
}

\section{PLEASE CITE THE PUBLISHED VERSION}

http://dx.doi.org/10.1002/app.41448

\section{PUBLISHER}

(c) Wiley Periodicals, Inc.

\section{VERSION}

AM (Accepted Manuscript)

\section{PUBLISHER STATEMENT}

This work is made available according to the conditions of the Creative Commons Attribution-NonCommercialNoDerivatives 4.0 International (CC BY-NC-ND 4.0) licence. Full details of this licence are available at: https://creativecommons.org/licenses/by-nc-nd/4.0/

\section{LICENCE}

CC BY-NC-ND 4.0

\section{REPOSITORY RECORD}

Mascia, Leno, Jane Clarke, Kiat S. Ng, Kok Sien Chua, and Pietro Russo. 2014. "Cure Efficiency of Dodecyl Succinic Anhydride as a Cross-linking Agent for Elastomer Blends Based on Epoxidized Natural Rubber". Loughborough University. https://hdl.handle.net/2134/17399. 


\title{
CURE EFFICIENCY OF DODECYL SUCCINIC ANHYDRIDE AS A CROSS- LINKING AGENT FOR ELASTOMER BLENDS BASED ON EPOXIDIZED NATURAL RUBBER
}

Leno Mascia $*^{a}$, Jane Clarke ${ }^{a}$, Kiat Seong $\mathrm{Ng}^{a},{ }$ Kok Sien Chua ${ }^{a}$, Pietro Russo $^{b}$

a) Department of Materials, Loughborough University, Loughborough LE11 3QL, U.K

b) Institute of Polymers, Composites and Biomaterials, National Research Council, Via Campi Flegrei 34, 80078 Pozzuoli, Naples, Italy

*Corresponding author: L.Mascia@lboro.ac.uk

\begin{abstract}
Blends of a highly epoxidized natural rubber (ENR50) with unmodified natural rubber (NR) and ethylene propylene elastomers (EPDM) were produced to evaluate the mixing and curing characteristics. Dodecyl succinic anhydride was used to cross-link the ENR50 component and the reactivity was assessed by monitoring the evolution of the torque in an oscillatory coaxial cylinder rheometer, as well as by DSC thermal analysis. A physical model was used to obtain a single parameter for the reactivity of the system, which corresponds to the rate constant for first order curing reactions. Although the blends were thermodynamically immiscible, displaying no significant change in $\mathrm{Tg}$, the components were well dispersed at microscopic level. Better mechanical properties were obtained for blends with EPDM.
\end{abstract}

Keywords: Epoxidized natural rubber, Blends, Anhydride cure, Natural rubber, Dodecyl succinic anhydride.

\section{Introduction}

Epoxidized natural rubber (ENR) has been known for some time and is commercially available in three grades, respectively known as ENR10, ENR25 and ENR50, where the integer denotes the mol\% of epoxide groups incorporated into the backbone of the polymer chains of natural rubber (NR) [1,2]. Epoxidation of NR can be carried out either in solution 
or from the latex using specific amounts of peroxy formic acid to control the degree of conversion [3-5]

The presence of epoxy groups in the chain increases the polarity, giving rise to enhanced adhesion characteristics and oil resistance, but also to an increase in glass transition temperature up to $-24{ }^{\circ} \mathrm{C}$ for ENR50 [3,4]. The epoxy groups sited along the polymer chains enhance the compatibility of ENR with polar polymers, such as polyvinyl chloride and polyamides for the production of blends [6,7]. Ouhadi et al. have demonstrated that the choice of vulcanizing agent can have a significant effect on properties (such as compression set, oil resistance and the tensile strength) of a TPV system obtained from blends of polypropylene (PP) and ethylene propylene diene monomer elastomer (EPDM) [8]. Since the use of a peroxide initiator for chemically binding the two components gives rise also to two simultaneous side reactions, i.e. crosslinking of EPDM phase and degradation of the PP component the amount of peroxide added and processing conditions have to be carefully controlled to obtain the desired reactions balance [7].

Halimatuddahliana et al. [9] have compared the properties of ternary blends of PP/EPDM/NR and PP/EPDM/ENR, produced by conventional compounding and vulcanization and have found that although the oil resistance of the PP/EPDM/ENR system was better than that shown by PP/EPDM/NR blends, the latter system exhibited better tensile properties.

Owing to the dual functionality of the epoxy groups in ENR, other researchers have directed studies to the development of novel self-vulcanizable blends based on mixtures of ENR with other functionalized polymers, such as carboxylated nitrile rubber and chlorosulfonated polyethylene, omitting the use of conventional vulcanizing agents. [2, 12,13]. Pire et al [3,4] have produced self-vulcanizing rubber systems from ENR with different epoxide content using dodecanedoic acid (DDDA, a dicarboxylic acid) as curing agent. These authors have found an enormous acceleration effect on the cure rates by the incorporation of an auxiliary agent, 1-2 dimethyl imidazole (DMI) at 2:1 molar ratio with DDDA [4]. The effect was attributed to the formation of the corresponding ammonium dicarboxylate salt, which can more readily open the oxirane ring than the corresponding acid.

In the present study the authors examine the use of dodecyl succinic anhydride (DDSA) as a crosslinking agent for mixtures of ENR with NR and EPDM respectively, as well as exploring the potentiality of ENR for the production of TPV-type systems, consisting 
of heterogeneous mixtures containing a cross-linked elastomer as the main component and a linear polymer to impart melt flow characteristics. At the same time, the pendant dodecyl segments from the DDSA that will be present in the cross-links are expected to provide internal plasticization, through a screening effect on polar groups within the chains, as well as providing a compatibilization mechanism for blends with hydrocarbon elastomers. The expected difference in the cross-links inherent to the two systems is illustrated in Figure 1.
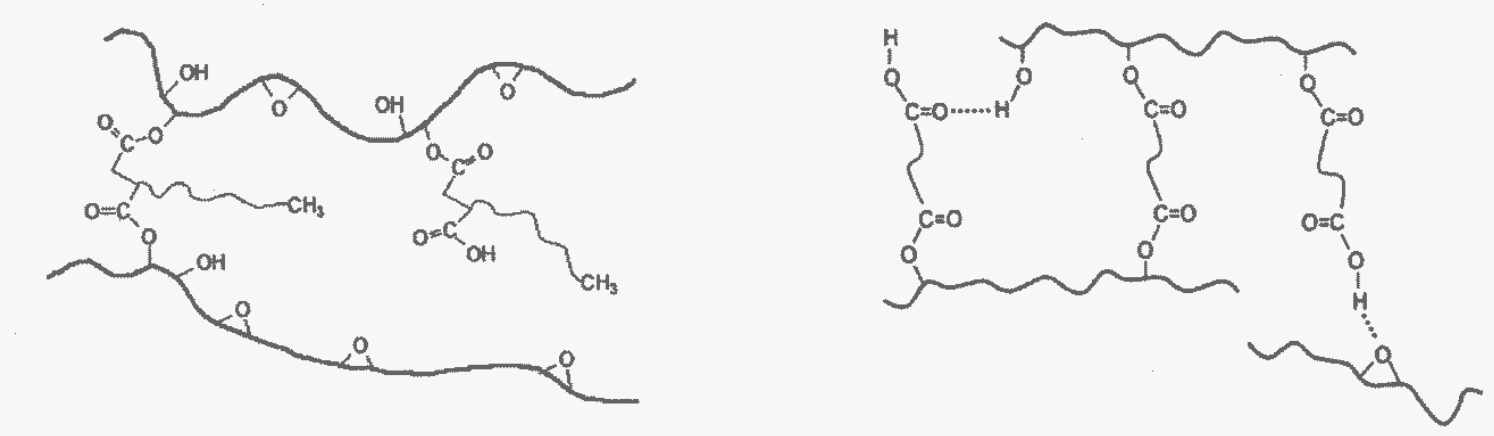

Figure 1: Formation of crosslinks in ENR through the reaction of epoxy groups with DDSA (Present study - Left) and with the carboxylic groups in dodecanoic diacid (Pire et al. -Right) [3]

The high epoxy content grade ENR50 was used in the present study in order to achieve the maximum possible reaction rates during processing from the available ENR systems. The amount of anhydride used was set at $7 \mathrm{w} \%$, which represents the estimated amount required to nominally produce one cross-link per 100 carbon atoms along the polymer chain (excluding the methyl group) at full esterification.

\section{Experimental}




\section{Materials}

a) Epoxidized Natural Rubber (ENR50, Epoxyprene 50, Mooney viscosity ML(1'+4')100 ${ }^{\circ} \mathrm{C}$ = 70 - 90, Manufactured by Muang Mai Guthrie Public Limited Company of Thailand) and Natural Rubber (Standard Malaysian Rubber CV 60, were generously provided by Tun Abdul Razak Research Centre.

b) (2-Dodecene-1-yl) succinic anhydride (DDSA), Xylene and N, N-Dimethylbenzylamine (DMBA) were obtained from Sigma-Aldrich.

c) Precipitated silica, (Ultrasil VN2) was obtained from Evonik Degussa Industries.

d) EPDM, Vistalon 7500 (high molecular weight grade, $56 \%$ ethylene and $5.7 \%$ ethylidene norborene) was obtained from Exxon Mobil Chemicals

\section{Mixing procedure}

The catalyst for the esterification reactions, N, N-Dimethylbenzylamine (DMBA), was used at 2 parts per hundred parts (polymer + anhydride) in all cases. The DMBA was premixed with amorphous silica, at 1: 0.7 weight ratio, to facilitate handling of this liquid during the preparation of the blends.

$50 \mathrm{~g}$ of TPV-type mixes were prepared in a Haake Rheomix laboratory internal mixer, fitted with Banbury rotors, at $80 \mathrm{rpm}$ in all cases. The mixes were obtained under two widely different conditions, respectively $160{ }^{\circ} \mathrm{C}$ for 15 minutes ("Severe” thermal conditions) and 80 ${ }^{\circ} \mathrm{C}$ for 10 minutes ("Mild” thermal conditions). It should be noted the non-crosslinkable linear polymer component in these mixes is another elastomer instead of a crystalline thermoplastic, which is usually found in commercial products. This type of composition was deliberately chosen to produce softer rubbers. Similar systems were studied by Wang et al. using EPDM as the cross-linkable component and a poly(ethylene-co-octene) rubbery linear polymer [10]. The presence of dispersed cross-linked EPDM domains were found to provide considerable improvements in the tensile strength and tear resistance over those exhibited by the pristine poly(ethylene-co-octene).

It should be noted that in the present studiy based on ENR 50 as the vulcanizable component, EPDM was used as the linear polymer component, instead of an EP copolymer, in order to provide sites for additional cross-linking reactions by a free radical mechanism. These reactions can be expected to take place simultaneously to the anhydride curing reactions, as in the present case, or by a sequential enhanced vulcanization procedure that would make 
use of a suitable peroxide initiator (not included in this study). The latter systems would offer the possibility of tailoring the network of these types of rubber blends in such a way that one phase can be more highly cross-linked than the other.

In the present study the mixes were produced as simple ENR/anhydride binary compositions and also as blends with NR and EPDM at 25 and $50 \mathrm{w} \%$ levels with respect to the total ENR/anhydride content. All components were mixed with the rotors set at the required speed (80 rpm) by feeding the main polymer component first and allowing about 1 minute before lowering the ram to close the mixing chamber. The torque and temperature were recorded continually and the data stored.

An additional ad hoc experiment was carried out to examine the likelihood of the formation of cross-links through etherification reactions, catalyzed by the tertiary amine DMBA. For this purpose 4 parts per hundred DMBA were added to the ENR50, (instead of 2 parts used in the mixture with DDSA) and the mixing (at $160{ }^{\circ} \mathrm{C}$ ) was extended to 20 minutes, as a means enhancing the propensity of interactions between the epoxy groups in ENR50 and the tertiary amine group in DMBA.

\section{Curing evaluation}

A commercial apparatus, known as the Wallace precision cure analyzer (abbreviated to Wallace analyzer), was used to study the post-mixing cure characteristics of the blends by monitoring the torque evolution with respect to time, at $1.7 \mathrm{~Hz}$ frequency and 0.44 strain setting. This procedure was used to determine the residual reactivity of the pre-vulcanized mixes as a means of estimating the additional curing requirements to complete the reactions. The cure temperatures used were $180^{\circ} \mathrm{C}$ and $200^{\circ} \mathrm{C}$ and the tests were carried out for up to 30 minutes. These were deemed to represent limiting practical conditions for possible industrial exploitation of the systems.

Approximately $2 \mathrm{~g}$ samples were cut from the mix and placed in the chamber of the Wallace analyzer. The evolution of torque with time was recorded automatically and the data were stored for analysis.

The Wallace analyzer consists essentially of a combination of a coaxial cylinder rheometer and a parallel disc oscillatory rheometer [13]. 
For the coaxial cylinder component the shear strain in the hoop direction is given by the displacement gradient across the gap (Ro - Ri), i.e. $\gamma=\frac{d S}{d r}$. When the gap is very small the shear strain across the gap is constant so that $\gamma=\mathrm{S} /(\mathrm{Ro}-\mathrm{Ri})$, where $S$ is the peripheral displacement at the surface of the oscillating cylinder. The corresponding shear stress $\tau$ is calculated from the torque $\mathrm{T}$ developed by the oscillatory cylinder to maintain the pre-set angular displacement, using the equation $\tau=\mathrm{T} / 2 \pi R o^{3}$.

The shear strain and shear stress acting in the hoop direction in the parallel plate component of the rheometer increase linearly from zero at the center to a maximum at the edge. Reference values can be calculated from the peripheral displacement gradient and the corresponding torque recorded in the measurements, i.e. $\gamma(R)=S(R) / h=2 \pi \Omega R / h$ and $\boldsymbol{\tau}(R)=$ $3 \mathrm{~T} / 2 \pi \mathrm{R}^{3}$, where $S(R)$ is the peripheral oscillation displacement, $h$ is the gap distance, $\Omega$ is the angular displacement of the spindle, $\mathrm{T}$ is the torque and $\mathrm{R}$ is the radius of the oscillating disc.

Since the denominator terms of the equations used to calculate the shear stress are the same for both components of the rheometer, resulting from $\mathrm{Ro} \approx \mathrm{Ri} \approx \mathrm{R}$, the shear stress at the edge of the parallel plate is equal to the value across the gap in the co-axial cylinder component, hence no discontinuity is expected at in the variation of the stress at the intersection. From the given equations it is estimated that the torque at the edge of the parallel plate is one third the value across the gap of the co-axial cylinder. In view of the linear decrease of the torque from the edge to the center of the parallel plate component the average contribution to the total torque is effectively $1 / 6$ of the torque for the coaxial cylinder. Consequently the co-axial cylinder is the dominant component of the rheometer and, therefore, for the purpose of the analysis the influence of the parallel plate can be considered an "edge effect" that gives rise to overestimates of the shear stress acting across the gap. It is well known that the reactions leading to gelation of low molecular weight thermosetting systems are autocatalytic due to the cage effect on the mobility of the activated species while approaching gelation conditions. In a recent study on the low temperature curing of systems based on epoxy resins Lionetto et al. have shown that the increase in viscosity with time can be described by the following equation [14]:

$$
\eta=\eta_{0} e^{\theta t}
$$

where $\eta=$ viscosity at time $t$ 


$$
\begin{array}{ll}
\eta_{0} & =\text { initial viscosity of resin mixture } \\
\theta & =\text { reactivity parameter }
\end{array}
$$

The applicability of such equation has been attributed to the equivalence of time and temperature with respect to the activation energy required for the events leading to gelation. However, the measurements on the systems of this work are performed to examine the curing behavior after the onset of gelation and, therefore, the progress of the cross-linking reactions that follows can be followed by monitoring the increase in modulus from an originally very low value, i.e. tending to zero. The evolution of the torque after gelation can be described using a time retardation function based on the premise that the formation of additional crosslinks during cure is retarded by the loss of mobility of the reactive chains and in concordance with a similarly controlled retardation caused by the reduction in the concentration of reactive species. Since the increase in modulus during curing is proportional to the rate of crosslinking reactions, the process can be described by the following equation:

$$
G_{(t)}=G o+\left[G_{\infty}-G o\right]\left(1-e^{-\theta t}\right) \ldots \ldots \ldots \ldots \ldots \ldots \ldots \ldots \ldots \ldots \ldots \ldots \ldots \ldots
$$

where $G_{(t)} \quad=$ shear modulus at time $t$

$G_{\infty} \quad=$ shear modulus at full reaction

$\Theta \quad=$ reactivity factor for curing reactions

$G_{0} \quad=$ shear modulus at $t=0$, where $G_{\infty} \gg G o$, thus $G o \approx 0$

This equation has the same basis as that used to describe the kinetics of $1^{\text {st }}$ order reactions in terms of the degree of conversion [15], expressed by

$$
\alpha(t)=\alpha(\infty)\left[1-e^{-k t}\right] \ldots \ldots \ldots \ldots \ldots \ldots . .3
$$

where $\alpha(t)$ is the degree of conversion at time $(t), \alpha(\infty)$ is the ultimate degree of conversion and $k$ is the rate constant for the reaction. Analogously, this equation also assumes that $\alpha(\infty)>>\alpha(o)$, the initial degree of conversion.

The equivalence of the equations 2 and 3 implies that any increase in the degree of conversion brings about a proportional increase in the shear modulus, which results from concomitant restrictions on the mobility of segments within polymer chains.

In view of the dynamic operating mode of the Wallace analyzer, that is to say that the imposed signal follows a sinusoidal function, the modulus has to be taken to represent the 
complex modulus $G^{*}$. The increase in $G^{*}$ s expected to result from the larger increase in the elastic component $G$ ' over the decrease in the values for the loss component $G$.”

The above equation can be rewritten as follows:

$$
\begin{aligned}
& \frac{G_{\infty}-G_{(t)}}{G_{\infty}-G o}=\frac{1}{e^{\theta t}} \quad \ldots \ldots \ldots \ldots \ldots \\
& \frac{G_{\infty}-G o}{G_{\infty}-G_{(t)}}=e^{\theta t} \quad \ldots \ldots \ldots \ldots \ldots
\end{aligned}
$$

As the shear modulus $G$ is directly proportional to the torque (T), measured in the curing experiments, a plot of $\log \left(\frac{T_{\infty}-T o}{T_{\infty}-T_{(t)}}\right)$ against 'time' would yield a linear relationship with the gradient of the curve corresponding to the reactivity factor $\frac{\theta}{2.303}$. The term $\mathrm{T}_{\infty}$ refers to the torque at the plateau (full reaction) in the torque-time curve, while $\mathrm{T}_{(\mathrm{t})}$ is the torque at time $\mathrm{t}$.

The advantage of using this procedure for the treatment of the raw torque data recorded by the curometer, therefore, lies primarily on the possibility to obtain a single parameter for comparing the reactivity of different systems.

It should be noted that, due to the alleviation of the errors related to the values of the torque at numerator and denominator of the equation, the ratio $\left(\frac{T_{\infty}-T o}{T_{\infty}-T_{(t)}}\right)$ becomes very close to the ratio of the corresponding shear modulus terms in equations 4 and 5.

\section{Gel content measurements}

Solvent extractions in boiling xylene were used to determine the gel content of the blends after mixing. Since xylene is a suitable solvent also for dissolving all individual components i.e. ENR, DDSA, EPDM and NR, it can be presumed that, in the absence of any other extraneous cross-liking reactions, the resultant gel content only consists of insoluble cross-linked DDSA/ENR, considering that the amounts of silica and accelerator used are small and within the expected experimental error.

For each sample, approximately $0.2 \mathrm{~g}$ to $0.3 \mathrm{~g}$ of specimen were cut and weighed before placing it into an aluminum (125 mesh) pouch of known weight. The specimens were then 
directly immersed into about $150 \mathrm{ml}$ of xylene in a $250 \mathrm{ml}$ round bottom flask attached to a condenser and heat was applied to boil the xylene for 2 hours. The pouches were taken out and dried in a vacuum oven at $100^{\circ} \mathrm{C}$ for 3 hours and then weighed. Three measurements of gel content for each sample were converted to w\% fractions, using equation 6 . In the case of blends was also estimate the normalized gel content (relative to the amount of reactive components).

$$
\text { Gel content }(w \%)=\frac{\text { Weight of residue }}{\text { Original weight of sample }} \times 100 \ldots \ldots \ldots \ldots \ldots \ldots
$$

\section{Thermal analysis}

A Mettler Toledo DSC 1 apparatus was used in nitrogen atmosphere to produce thermograms, respectively from room temperature to $240{ }^{\circ} \mathrm{C}$ and from -50 to $+20{ }^{\circ} \mathrm{C}$.

\section{Measurements of tensile stress-strain relationship}

Tensile tests were carried out using a laser equipped Houndsfield tensometer model 500L according to the ASTM D412 method. These tests were performed to assess primarily the strain hardening characteristics of the systems examined, as the actual values for the derived modulus and strength would not be particularly meaningful for systems that do not contain all the required additives and auxiliaries that would be expected in a fully formulated TPV system. Dumbbell shaped specimens with $27 \mathrm{~mm}$ of gauge length and $4 \mathrm{~mm}$ of width were cut with a hydraulic press cutter from $1 \mathrm{~mm}$ thick molded plaques prepared by compression molding. (These were prepared at $160{ }^{\circ} \mathrm{C}$ in a hydraulic press using a 5 minutes total heating/cure time). Tensile tests were performed at ambient conditions $\left(21^{\circ} \mathrm{C}\right)$ employing a crosshead speed of $100 \mathrm{~mm} / \mathrm{min}$ up to fracture. From the recorded force and extension the data were converted into nominal stress/strain curves, without allowing for specimen thinning and the excess deviations from the requirements of rubber elasticity theory for the calculation of strain.

Note that the gel content of the molded samples was not measured as the tensile tests were carried out only on samples produced under "severe" thermal conditions, which had already 
reached the maximum. Any further reaction taking place during pressing of the plaques would be expected to have increased only the cross-linking density of the gel.

\section{SEM Examinations}

Examinations of the morphological structure of the various systems were made using a Carl Zeiss (Leo/Cambridge) Stereoscan 360 scanning electron microscope (SEM) with an operating voltage of $10 \mathrm{kV}$. Compression molded specimens were cryogenically fractured after immersion in liquid nitrogen and small pieces were mounted on aluminum stubs with the fractured surface on the upper side and sputter-coated with a thin layer of gold.

\section{Results and Discussion}

Although the mixing characteristics of the systems examined were not a primary concern of this study, it is worth reporting the appearance of a broad peak in the recorded values of the torque upon reaching the steady state mixing regime. This feature can probably be associated with the onset of the reactions between ENR 50 and DDSA and could be used as a process control parameter for these systems.

\section{Raw data for the evolution of cure}

In Figure 2 are shown the traces representing the torque evolution for systems produced under "mild" thermal conditions, monitored with the Wallace analyzer for curing experiments at $180{ }^{\circ} \mathrm{C}$ (Right side) and at $200{ }^{\circ} \mathrm{C}$ (Left side). These indicate that only the runs at $200{ }^{\circ} \mathrm{C}$ are quite close to reaching the equilibrium state before the end of the cure cycle, however in both cases there is a clear evidence of the catalytic effect of DMBA on the curing reactions. For the same systems produced under "severe" thermal conditions the traces reach a plateau well within the 30 minutes run (see Figure 3). 

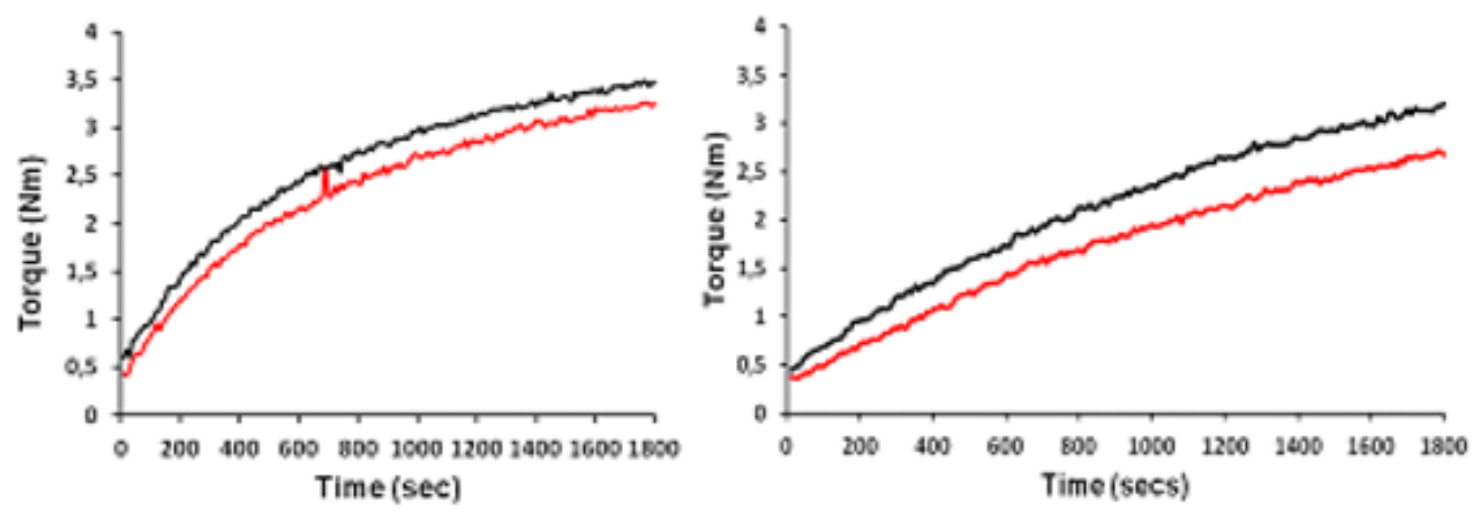

Figure 2: Curing torque-time curves for 97ENR/7DDSA systems, mixed under "mild" thermal conditions. Left: Measurements at $200{ }^{\circ} \mathrm{C}$. Right: Measurements at $180{ }^{\circ} \mathrm{C}$ - — with DMBA, — without DMBA.

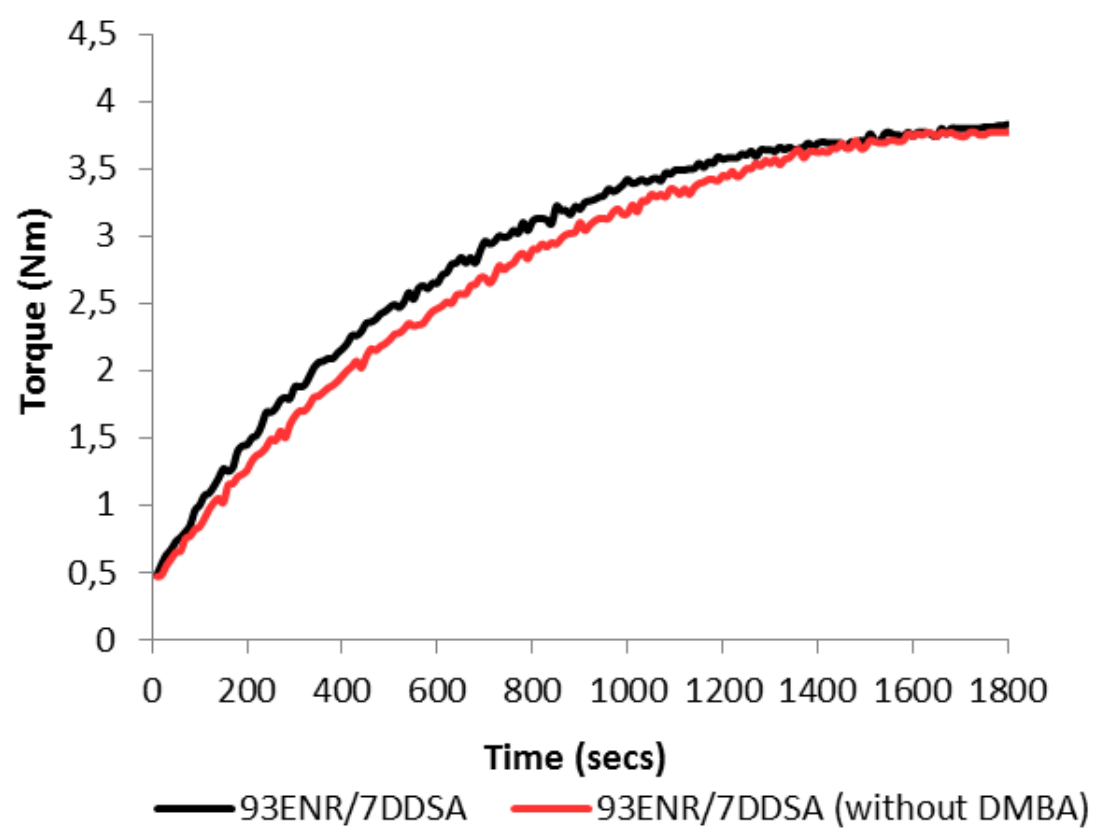

Figure 3: Curing torque-time curve at $200{ }^{\circ} \mathrm{C}$ for $97 \mathrm{ENR} / 7 \mathrm{DDS}$ A systems (with and without DMBA), both mixed under "severe" thermal condition.

The merging of the torque traces towards the end of the curing cycle in Figure 3 can be explained by the results on thermal analysis (see Figure 6), which reveal the occurrence of extensive degradation after the peak. Since at around $200{ }^{\circ} \mathrm{C}$ these exotherms are considerably more pronounced for systems containing the DMBA catalyst, the flattening of 
the torque traces at the upper end of the run in the Wallace analyzer can be associated with the beginning of the breakdown of the network. Recent results from more detailed studies currently carried out on these systems seem to indicate that the secondary exotherms arise from the breakdown of the network through decarboxylation reactions (data to be reported in the near future).

\section{Analytical treatment of the curometer data}

In all cases the initial torque (i.e. at $\mathrm{t}=0$ ), was assumed to be equal to zero since it is difficult to estimate the precise values owing to the transient temperature regime in the initial stages of the runs and to the lack of accuracy inherent to the instrument in this range. In Figures 4 and 5 are shown plots of $\log \left(\frac{T_{\infty}-T o}{T_{\infty}-T_{(t)}}\right)$ against time obtained from rheometric cure measurements at $200{ }^{\circ} \mathrm{C}$ relative to binary blends of 93ENR/7DDSA, both with and without DMBA, mixed respectively under "severe” and “mild” thermal conditions.

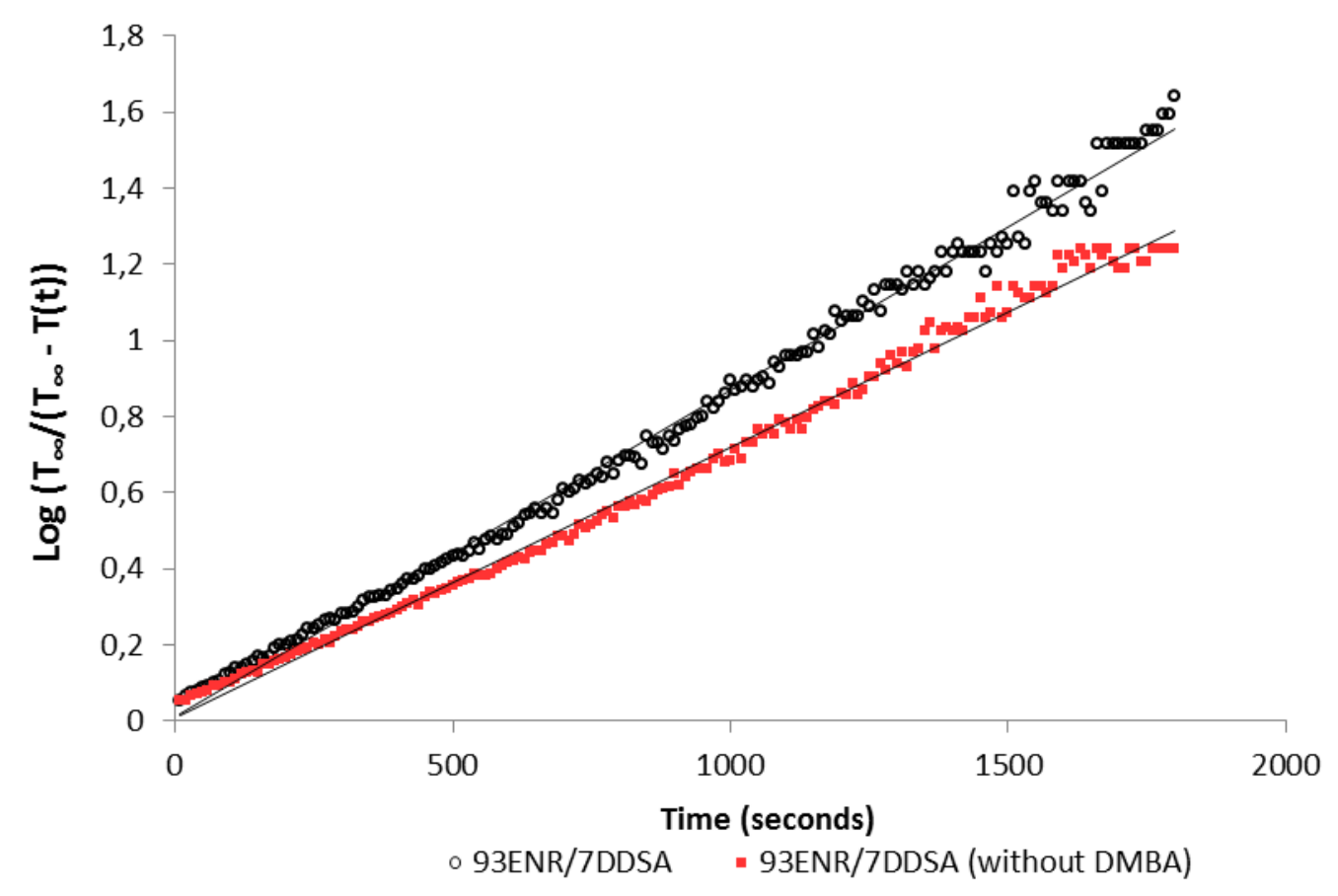

Figure 4: Plot of $\log \left(\frac{T_{\infty}-T o}{T_{\infty}-T_{(t)}}\right)$ against time for tests at $200^{\circ} \mathrm{C}$ carried out on the two binary blends 93ENR/7DDSA (i.e. with and without DMBA) prepared under "severe" mixing conditions ( $160{ }^{\circ} \mathrm{C}$ for 15 minutes). (Ref. 16, Reproduced with permission). 
The reactivity factor value, $\theta$, for the ENR/DDSA systems mixed under "severe" thermal conditions, obtained from the gradient of the straight line for the plots in Figure 4, has been found to increase from $1.61 \times 10^{-3} \mathrm{~s}^{-1}$ to $2.07 \times 10^{-3} \mathrm{~s}^{-1}$ with the addition of the DMBA catalyst. Note that the units for the reactivity factor may be taken to represent the rate constant for the curing reactions, normalized with respect to the final state of cure.

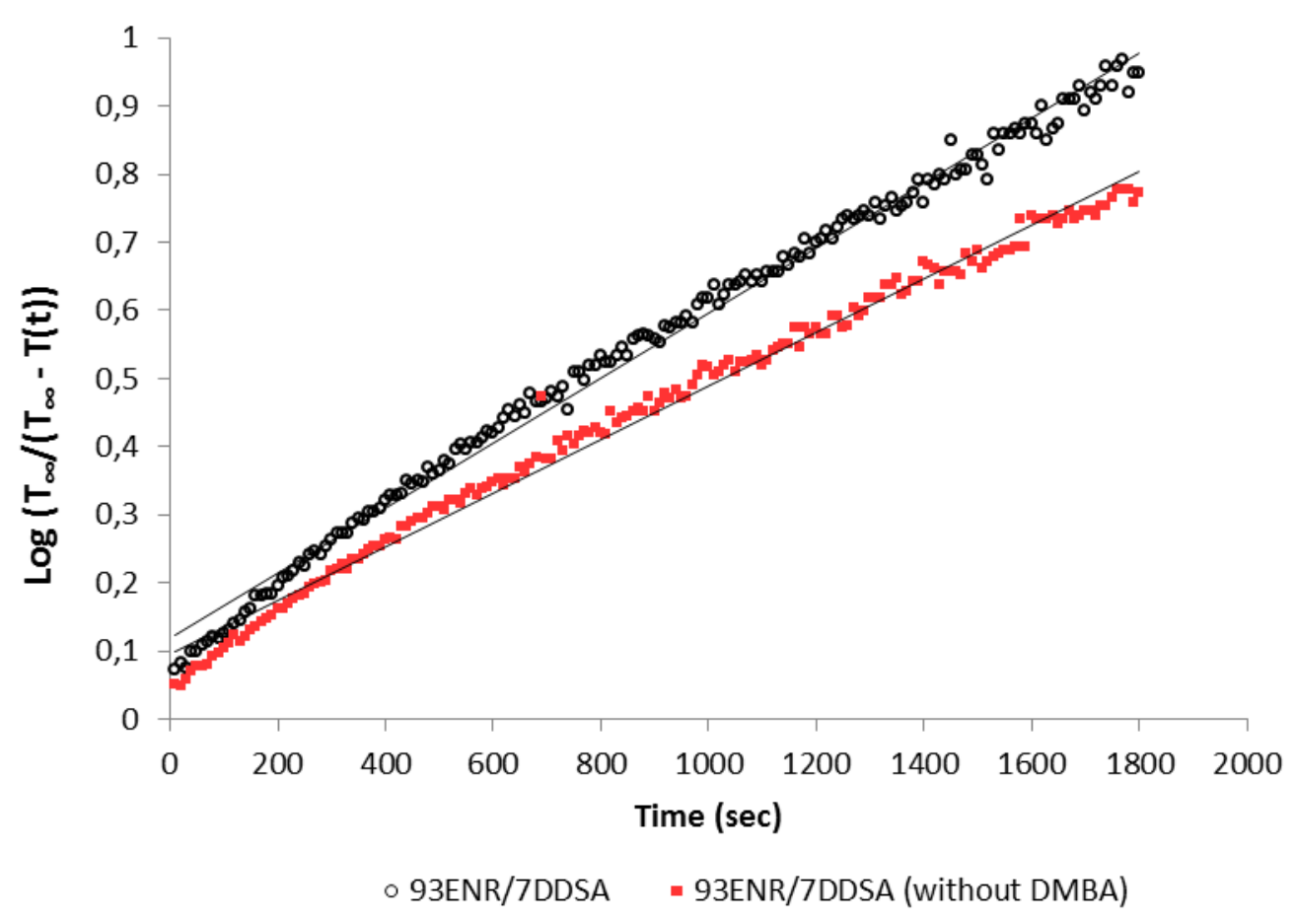

Figure 5: Plot of $\log \left(\frac{T_{\infty}-T o}{T_{\infty}-T_{(t)}}\right)$ against time for tests at $200^{\circ} \mathrm{C}$ carried out on the two binary blends 93ENR/7DDSA (i.e. with and without DMBA) prepared under "mild" mixing conditions ( $80{ }^{\circ} \mathrm{C}$ for 10 minutes).

From the plots in Figure 5 it is observed that, except from the small deviation for data up to about 300 seconds, there is a good fit to Equ. 5 also for the ENR/DDSA system mixed under "mild" thermal conditions. The respective values for the reactivity factor, $\theta$, increase from $0.92 \times 10^{-3} \mathrm{~s}^{-1}$ to $1.1510^{-3} \mathrm{~s}^{-1}$ for systems containing the DMBA catalyst, which confirm the strong catalytic effect of this additive on the cross-linking reactions. In comparing the data for the reactivity factor it is noted that, while the values are lower for mixes produced under "mild" mixing conditions, the increment resulting from the addition of the DMBA catalyst is approximately the same for both types of mixes. Hence, the higher values of the reactivity factor for the two systems produced under "severe" thermal history has to be associated with 
the more advanced state of the reactions at the beginning of the cure cycle, which are expected to reach the final state at a faster rate. At the same time, it can be deduced that the higher initial gradient of the plots in Figure 5 for systems produced under "mild" thermal conditions, is related to the lower initial gel content of these mixes (see later), which may display an autocatalytic behaviour before reaching full gelation, in accordance with Equ. 1

\section{Curing evaluations by thermal analysis}

In Figure 6 are shown DSC thermograms for systems produced under "severe" mixing conditions with scans at 1 and $5{ }^{\circ} \mathrm{C}$ /minute. These display clearly the catalytic effect of the DMBA additive on the curing reactions, evidenced in the form of sharp exothermic peaks respectively at around 162 and $185^{\circ} \mathrm{C}$. For the non-catalyzed system only a small primary endothermic peak can be identified for the run at the lower heating rate. Since the sharpness of the peak is related to the reaction rate in the first stage of the reactions, consisting mainly of ring opening and formation of monoesters, the absence of these features for non-catalyzed system must be taken as a confirmation that the operating reaction mechanism relies on the formation of the quaternary ammonium salt from the interaction of DDSA with DMBA, as also evidenced in the work by Pire et al. [4]. 


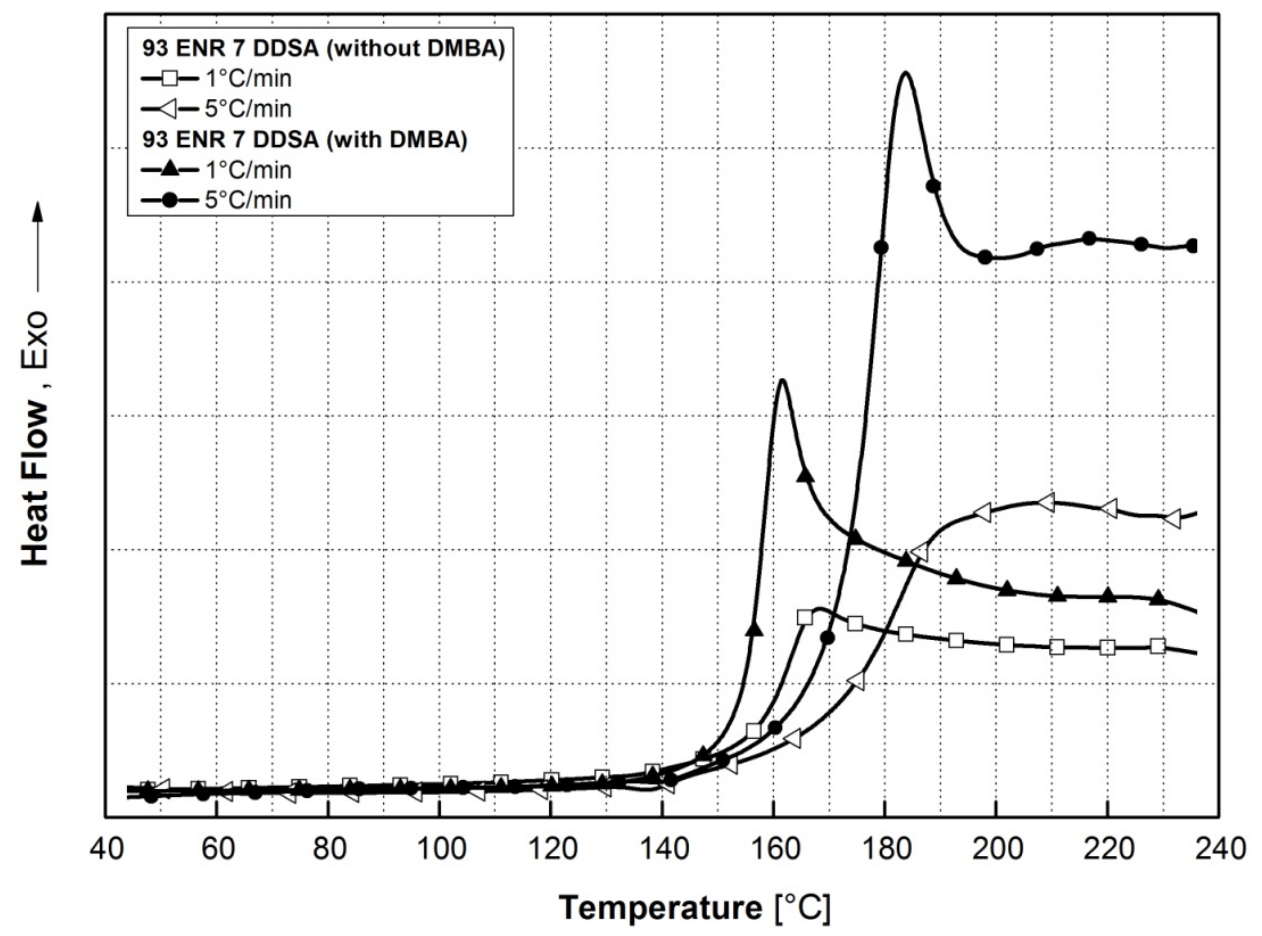

Figure 6. DSC thermograms for samples produced under "severe" mixing conditions, obtained with scans at 1 and $5^{\circ} \mathrm{C} / \mathrm{min}$ for both systems (i.e. with and without DMBA catalyst). (Ref. 16, Reproduced with permission).

The scans at the higher heating rates give rise to a small secondary exotherms in the region of $210-220{ }^{\circ} \mathrm{C}$ for both systems, which are indicative of additional exothermal reactions, possibly consisting of a combination of cross-linking and chain scission reactions. These features are presently addressed in a study aimed to clarify the chemical reactions involved through ATR and NIR analysis, which have also revealed the occurrence of extensive side reactions, particularly the formation of large quantities of vicinal diol groups in addition to those derived from the opening of the oxirane ring by the reaction with the anhydride.

\section{Gel content}

The results have shown that the gel content was negligible for all individual components; the highest recorded value was $1.01 \mathrm{w} \%$ gel for EPDM. Furthermore, the gel content was also negligible (1.88 w\%) for the particular ENR50 sample mixed only with 
DMBA at $160{ }^{\circ} \mathrm{C}$ for 20 minutes, thereby excluding the possibility of etherification reactions taking place prior to esterification reactions with the DDSA curing agent.

The measured gel content values and the related data for mixes produced under "severe" thermal conditions are presented in Table 1 . The maximum gel content recorded is about 88 w\%. The discrepancy from $100 \%$ can be attributed to the presence of non-functionalized NR in the original ENR component used (as mentioned earlier).

Table 1: Gel content results for all mixes produced under "severe" thermal conditions based on ENR/DDSA vulcanizing system. (Note: All systems contain DMBA, except where otherwise stated)

\begin{tabular}{|l|c|c|c|}
\hline Sample description & $\begin{array}{c}\text { Gel content } \\
\mathbf{( w \% )}\end{array}$ & $\begin{array}{c}\text { Normalized } \\
\text { Gel content } \\
\mathbf{( w \% )}\end{array}$ & $\begin{array}{c}\text { Incremented } \\
\text { Gel content } \\
\text { (w\%) }\end{array}$ \\
\hline 93ENR/7DDSA & 87.9 & - & - \\
\hline 93ENR/7DDSA (without DMBA) & 83.8 & - & - \\
\hline & & & 5.9 \\
\hline 70ENR/5DDSA/25NR & 70.4 & 93.9 & 13.2 \\
\hline 46.5ENR/3.5DDSA/50NR & 50.6 & 101.2 & 4.3 \\
\hline 70ENR/5DDSA/25EPDM & 69.2 & 92.3 & 20.5 \\
\hline 46.5ENR/3.5DDSA/50EPDM & 54.3 & 108.5 & \\
\hline
\end{tabular}

In examining the data in Table 1 it is noted that the normalized gel content of the blends is higher than the value expected from the reactions between the ENR50 and DDSA. Therefore, the incremented gel content (third column) has to be associated with the formation of additional cross-links by a free radical mechanism. However, these become significant only when the companion polymer is present at a high ratio with respect to the ENR50. In comparison with the data in Table 1 the gel content for the mixes produced under "mild" thermal conditions was slightly lower, falling within the range $81-84 \%$.

\section{Mechanical properties}

The nominal stress-strain curves for the binary ENR50/DDSA systems produced under "severe" mixing conditions displayed a generally low elongation at break, while those produced under "mild" thermal conditions exhibited low stress values without notable signs of a strain hardening behaviour. A typical nominal stress - strain curve for the binary system 
produced at $80{ }^{\circ} \mathrm{C}$ is shown in Figure 7. It should be noted that the molded plaques had a "rather lumpy texture" owing to the high gel content of the blend at the end of the mixing cycle, which limits the flow of the mix within the mold and provides an explanation also for the the rippled nature of the stress/strain curve.

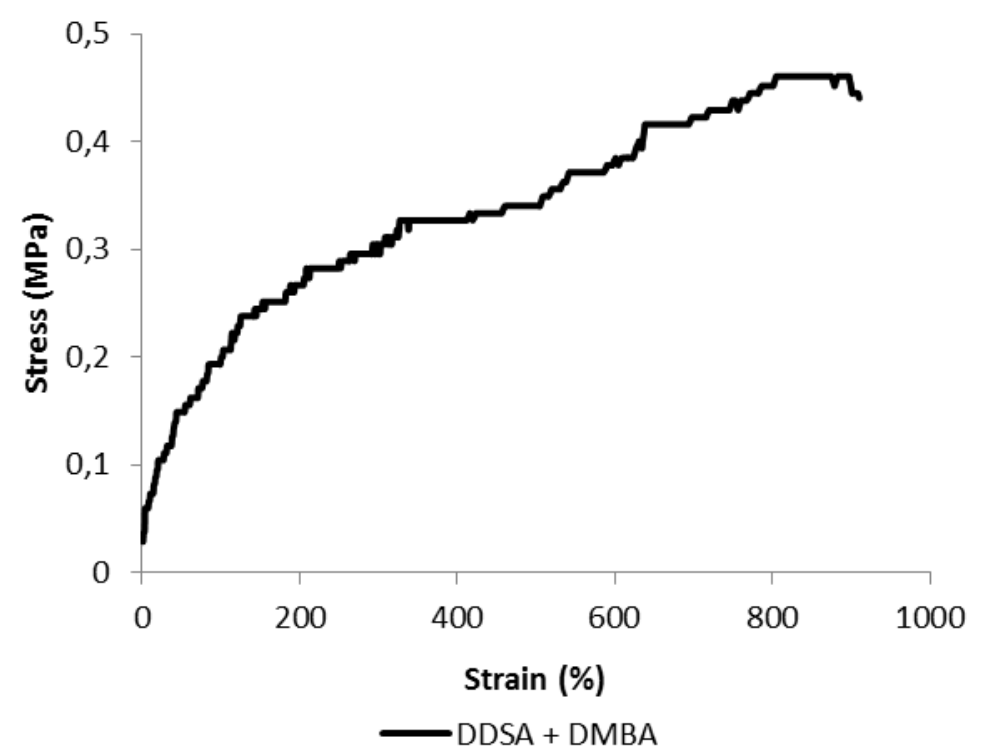

Figure 7: Nominal stress-strain curve for the catalysed ENR50/DDSA system prepared under "mild" thermal conditions (mixing at $80{ }^{\circ} \mathrm{C}$ for 10 minutes)

Better mechanical properties, particular with respect to strain-hardening characteristics, were achieved for the ternary blends, as shown in Figure 8.

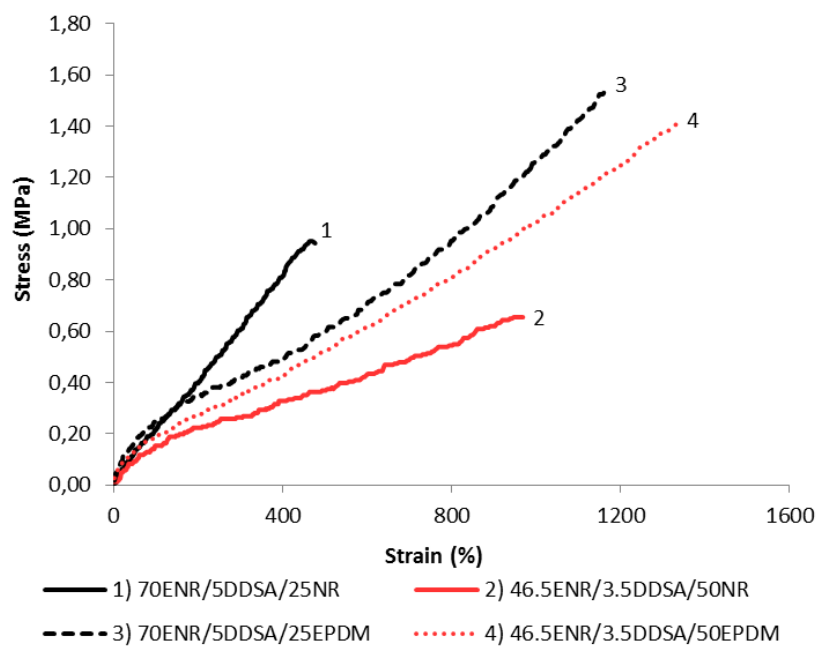


Figure 8: Nominal stress-strain curves for ternary systems derived from reactive mixtures of ENR/DDSA

As already indicated earlier the curves in Figures 7 and 8 for the stress-strain relationship representing mechanical properties of the various compositions based on ENR/DDSA are to be taken only as indicators of the mechanical behavior of the systems and are only useful to assess their suitability for the possible development of related elastomeric products. On this basis it is clear that blends with EPDM are displaying better characteristics than blends with NR. However, it is important to note that the state of cure of the blends in the molded plaques is far belowthe maximum level achievable for these systems and, therefore, the strength values are generally lower than would be expected at full cure.

\section{Thermal analysis at low temperatures}

The DSC thermograms in Figure 9 indicate that the Tg for the uncured (as received) ENR50 is $-21.9{ }^{\circ} \mathrm{C}$, while that the value for the sample prepared under "severe" mixing conditions (gel content $\sim 88 \%$ ) is $-19.0{ }^{\circ} \mathrm{C}$, which is somewhat higher than the original elastomer and suggests, therefore, that the use of DDSA curative does not induces the anticipated plasticization expected from the screening effect of the dodecyl segments in the cured elastomer. A small increase in Tg, however, is likely to arise purely as a result of the introduction of crosslinks and, therefore, plasticization may be counteracted by intermolecular attractions resulting from the formation of hughly polar groups, such as $\mathrm{OH}$ and $\mathrm{COOH}$ (see Figure 1). 


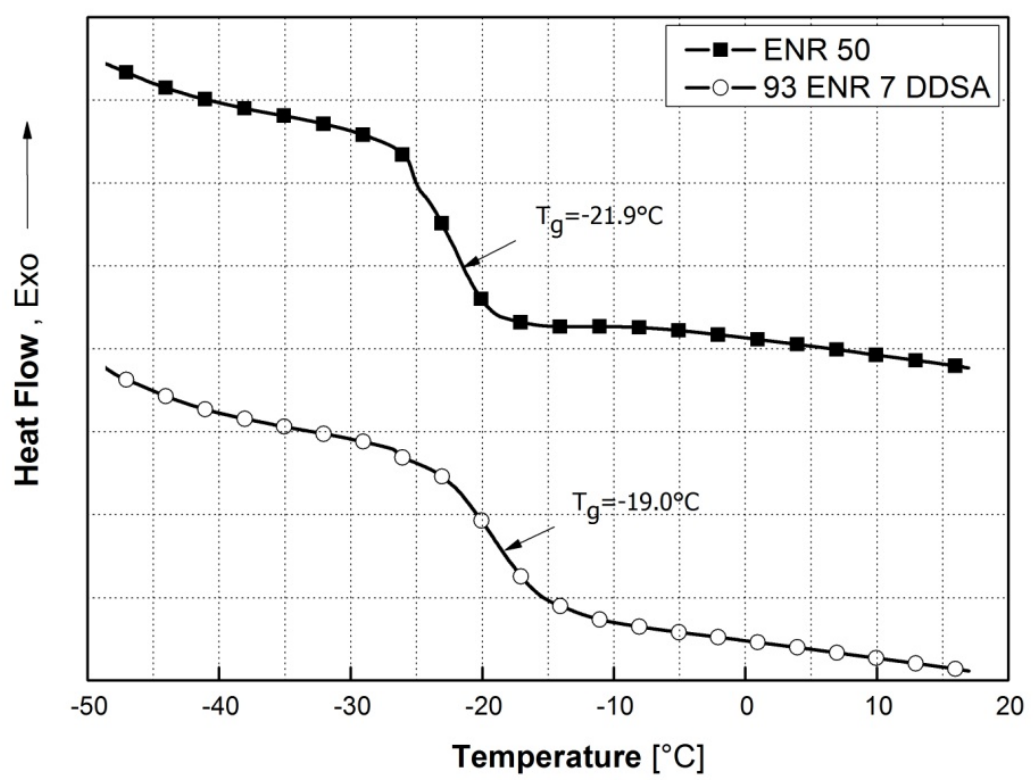

Figure 9. DSC thermograms at low temperatures for ENR50 (as received) and NR50/DDSA produced under “severe” mixing conditions (Ref. 16, Reproduced with permission).

\section{Morphology}

The SEM micrographs in Figure 10 show that the ENR/DDSA combination and ENR/DDSA/NR blends containing up to $50 \mathrm{w} \% \mathrm{NR}$ are well homogenized. 
a)

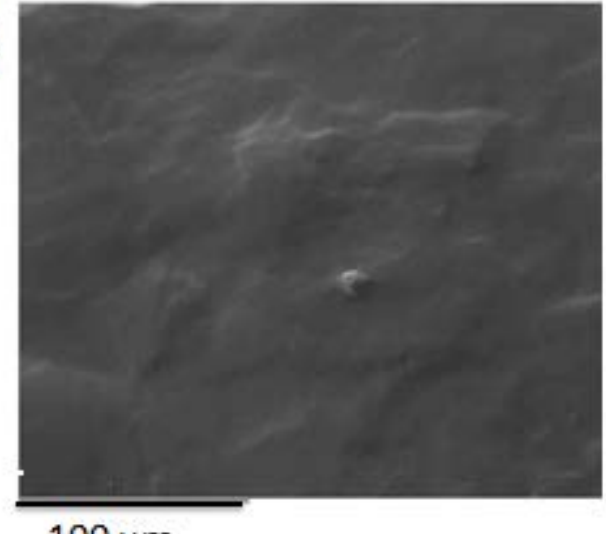

$100 \mu \mathrm{m}$

c)

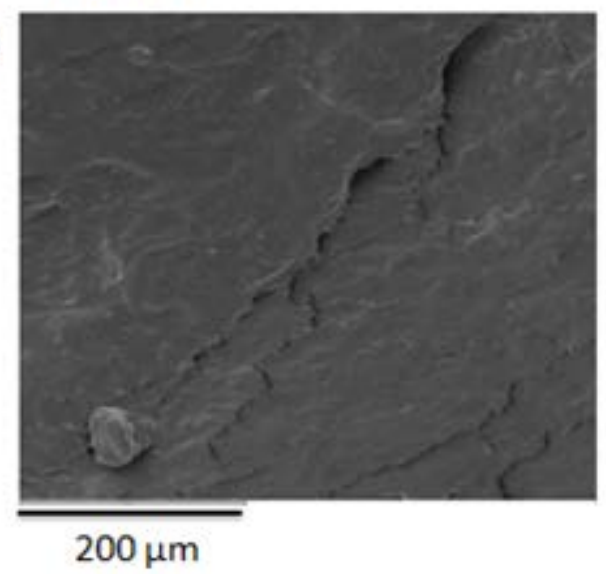

b)

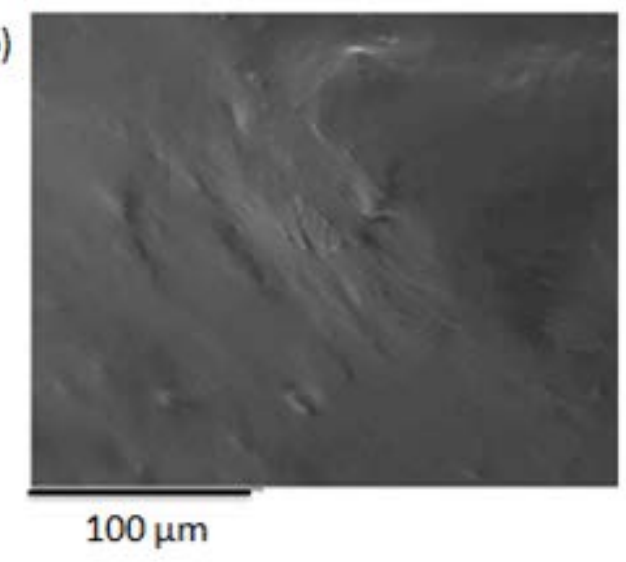

d)

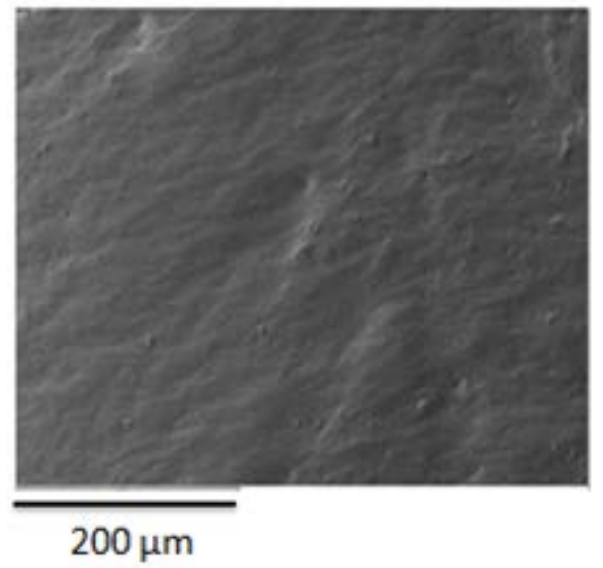

Figure10: SEM micrographs for the 93ENR/7DDSA system (a) and blends 46.5ENR/3.5DDSA/50NR (b), 69.75ENR/5.25DDSA/25EPDM

(c) and 46.5ENR/3.5DDSA/50EPDM (d).

The blends with EPDM, appear to be slightly more heterogeneous but are well compatibilized, as indicated in the micrograph taken at higher magnification for the system with 50\% EPDM content. The Tg values obtained by DSC thermal analysis for the $50 \%$ blends are $-16.0{ }^{\circ} \mathrm{C}$ with EPDM and $-16.5{ }^{\circ} \mathrm{C}$ with NR, which are slightly higher than the values obtained for the corresponding ENR50/DDSA mixture. At the same time the Tg values indicate that neither two uncross-linked elastomers is miscible with the ENR50, as these would have been expected to reduce the $\mathrm{Tg}$ in view of the much lower inherent Tg values of both $\mathrm{NR}$ and EPDM. 


\section{Conclusions}

Mixtures of epoxidized natural rubber (ENR50) and dodecyl succinic anhydride (DDSA), using molar amounts to produce one nominal cross-link for every $100 \mathrm{C}$ atoms in the backbone of the polymer chains at full esterification, were produced in a Haake Rheomix laboratory internal mixer. For the mixing conditions used the gel content was found to be within the range $81-88$ w\%. The curing behavior of the mixtures was monitored by following the evolution of the torque in the oscillatory Wallace analyzer and the data were fitted to a physical model that can be correlated with $1^{\text {st }}$ process for the development of crosslinks. The reactivity factor, $\theta$, which is synonymous with the rate constant for the curing reactions, was obtained from plots of $\log \left(\frac{T_{\infty}-T o}{T_{\infty}-T_{(t)}}\right.$ against time. Higher $\theta$ values were obtained for mixes produced under "severe" thermal conditions than the corresponding systems that received a "mild" thermal treatment during mixing. Irrespective of the thermal conditions used in preparing the mixture, an increase of about $25 \%$ in reactivity was revealed by the addition of DBMA as a catalyst for the curing reactions. The DSC thermal analysis for the residual reactivity of the systems after mixing, confirms the significant catalytic effect exerted by the DBMA additive. Blends were also produced using different amounts of natural rubber and EPDM respectively. Although a fairly high degree of homogeneity at microscopic level was achieved for both systems, the blends were thermodynamically immiscible. The blends with EPDM, however, displayed better mechanical properties.

\section{Acknowledgements}

This work has been partially supported by the POR Campania FSE 2007-2013 as part of the Materiali e Strutture Intelligenti (MASTRI) Project. The authors are also grateful to Tun Abdul Razak Research Centre for the generous donation of large quantities of ENR50.

\section{References}

1. X. Jiang, H. Huang, Y. Zhang, Y. Zhang, J. Appl. Polym. Sci., 92, 1437 (2004).

2. C. Nakason, S. Saiwari, J. Appl. Polym. Sci., 110, 4071 (2008).

3. M. Pire, S. Norvez, I. Iliopoulos, B.L. Rossignol, L. Leibler, Polymer, 51, 5903 (2010). 
4. M. Pire, S. Norvez, I. Iliopoulos, B. L. Rossignol, L. Leibler, Polymer, 52, 5243 (2011).

5. T. Johnson, S. Thomas, Polymer, 40, 3223 (1999).

6. M. Narathichat, C. Kummerlöwe,N. Vennemann, K. Sahakaro, C. Nakason, Adv. Polym. Tech., 31, 118 (2012).

7. C. Nakason, B. Thongnuanchan, K. Nokkaew, A. Kaesaman, Polym. Eng. Sci., 47, 421 (2007).

8. T. Ouhadi, S. Abdou-Sabet, H. Wussow, L.M. Ryan, L. Plummer, F. Baumann, J. Lohmar, H.H. Vermeire, Ullmann's Encyclopedia of industrial chemistry, Wiley-VCH Verlag GmbH and Co, Published online in 2004, p 454-464.

9. H.I. Halimatuddahliana, Polym. - Plast. Techn. Eng., 43, 357 (2004).

10. Z. Wang' 'X. Cheng” J. Zhao, Materials Chemistry and Physics, 126, 272 (2011).

11. S. Mukhopadhyay, S.K. De, J. Appl. Polym. Sci., 42, 2773 (1991).

12. S. Toki, T. Fujimaki, M. Okuyama, Polymer, 41, 5423 (2000).

13. J. Butler, P.K. Freakley, Rubber Chem. Tech., 65, 374 (1992).

14. F. Lionetto, L. Mascia, M. Frigione, Eur. Polym. J., 49, 1298 (2013).

15. P. Musto, G. Ragosta, G. Scarinzi, L. Mascia, Polymer, 45, 1607 (2004).

16. L. Mascia, P. Russo, M. Lavorgna, L. Verdolotti, J. Clarke, A. Vignali, D. Acierno, AIP Conf. Proc., 1599, 26-29 (2014): doi: 10.1063/1.4876769 
